\title{
Perceived Reactions of Elementary School Students to Changes in School Lunches after Implementation of the United States Department of Agriculture's New Meals Standards: Minimal Backlash, but Rural and Socioeconomic Disparities Exist
}

\author{
Lindsey Turner, $\mathrm{PhD}^{1,2}$ and Frank J. Chaloupka, $\mathrm{PhD}^{1,3}$
}

\begin{abstract}
Background: Updated standards for meals sold through the USDA's National School Lunch Program took effect at the beginning of the 2012-2013 school year. The current study assessed the perceptions of school staff regarding student reactions to these changes in school lunches and how perceptions varied across schools.

Methods: Mailback surveys were gathered from administrators and food service staff at a nationally representative sample of 557 US public elementary schools in the second half of the 2012-2013 school year.

Results: Half of the respondents (56.4\%) agreed that students complained about the meals at first, but $70 \%$ agreed that students like the new lunches. Perceived student complaints were significantly higher among respondents from rural schools $(n=184)$ than from urban $(n=127)$ or suburban $(n=171)$ schools. Respondents at rural schools also were more likely to report that they perceived that fewer students were purchasing the meals and that students were consuming less of the meals than during the previous year. Perceived student complaints were higher at schools not offering regular (i.e., higher-fat) pizza. Respondents at socioeconomically disadvantaged schools ( $>66 \%$ of students eligible for free/reduced-priced meals) perceived that more students were buying lunch and that students were eating more of the meal than in the previous year.

Conclusions: Perceptions of school personnel suggest reasonable acceptance of school lunches subsequent to revisions. Given the importance of offering healthful foods at school, the revised USDA meals standards are a promising strategy to improve the diets of children.
\end{abstract}

\section{Introduction}

$\mathbf{M}$ ost US children's diets exceed recommended levels of sugar, fat, and sodium ${ }^{1}$ and are deficient in fruits, vegetables, and whole grains..$^{2-4}$ Given the documented role of foods and beverages consumed at school in contributing to children's excessive intake of solid fats and added sugars, ${ }^{5}$ the school food environment has received much attention recently. Nationally representative data on school lunches from the School Nutrition
Dietary Assessment Study-IV in 2009-2010 showed that elementary school lunches as offered and served exceeded recommendations for average percentage of daily calories from solid fats and added sugars and fell short of recommended daily amounts of vegetables and whole grains. ${ }^{6}$

The majority of US public schools participate in the National School Lunch Program (NSLP), which is administered by the USDA, and provided meals to 31 million students in 2012. ${ }^{7}$ Until recently, USDA meals standards had not been

\footnotetext{
'Institute for Health Research and Policy, University of Illinois at Chicago, Chicago, IL.

${ }^{2}$ Present affiliation: College of Education, Boise State University, Boise, ID.

${ }^{3}$ Department of Economics, University of Illinois at Chicago, Chicago, IL.
} 
updated for 15 years, but as directed by the Healthy, HungerFree Kids Act of $2010,{ }^{8}$ the USDA revised the meals standards to align with the 2010 Dietary Guidelines for Americans. ${ }^{9}$ New standards were released in $2012,{ }^{10}$ requiring implementation in the 2012-2013 school year.

The updated USDA standards for lunches ${ }^{11}$ required that by 2012-2013 half of grains offered must be whole-grainrich products, with phase-in so that by 2014-2015 all grains are whole-grain rich. Both a fruit and a vegetable must now be offered daily, with a variety of vegetables to be served within a week, including dark green vegetables, red/orange vegetables, legumes, starches, and other vegetables. Milk is limited to nonfat or low-fat (1\%) milk (sweetened flavored milk is only allowed if nonfat). Limits on saturated fats did not change from the previous standards, but trans fats were limited to zero, and new targets for lower sodium content were established. Although the new USDA meal standards do not restrict any particular foods - such as those common in school meals and often high in fat, such as pizza and fries - in some schools these foods have been removed from menus or revised to better meet the nutritional standards. For example, some schools offer more-healthful versions of pizza by using lower-fat cheese, vegetables instead of meats for toppings, and whole-grain crusts.

The new standards bring the potential for major improvements in the quality of school lunches, but also created many implementation challenges for school and district food service personnel. ${ }^{12} \mathrm{~A}$ recent study by the Government Accountability Office (GAO) indicated that student participation in the NSLP dipped by $3.7 \%$ from 2010-2011 to 2012-2013 and concluded that decreased participation - which occurred mainly among full-pricepaying students - may have been the result of increased meal prices and/or decreased student acceptance of the new lunches. ${ }^{13}$ The GAO also surveyed state child nutrition directors during the summer of 2013, and respondents confirmed that implementing the new regulations had been challenging. ${ }^{13}$ Difficulties included challenges in planning new menus, increased costs resulting from more fruits and vegetables, and dealing with plate waste from food thrown away, rather than being consumed, by students. However, all respondents supported the goal of improving the nutritional quality of meals and agreed that the changes would facilitate such improvements.

Because the regulations are new, and relatively little is known thus far about implementation challenges, the aim of the current study was to assess the perceptions of elementary school administrators and food service personnel regarding students' reactions to the new lunches. Three topics were of interest: (1) perceived reactions of students regarding the new lunches; (2) variation in perceived reactions across schools; and (3) whether perceived reactions were associated with lunch meal characteristics. This study uses data gathered during 2012-2013 as part of the Bridging the Gap research program's survey of nationally representative samples of US public elementary schools.

\section{Methods}

\section{Overview}

Mailback surveys were conducted during the spring of the 2012-2013 school year. The project was reviewed and approved by the institutional review board at the University of Illinois at Chicago (Chicago, IL).

\section{Sample and Weights}

The sample was developed at the Institute for Social Research at the University of Michigan, based on a publicuse data set from the National Center for Education Statistics (NCES). ${ }^{14}$ All public elementary schools in the contiguous United States containing a third-grade class with at least 20 students were eligible for sampling. Among the sample of 1051 schools, 623 responded $(59.3 \%$ response rate). As a result of the focus on USDA lunch standards, only schools participating in the NSLP $(n=586)$ were included for these analyses. After 29 schools not providing data on lunches were omitted, a total of 557 schools were included in the analytic data set. Weights were developed to allow for inference to US elementary schools. After data collection, weights were adjusted for potential nonresponse bias through calibration that modeled school characteristics associated with propensity for nonresponse.

\section{Procedure}

Surveys were mailed to principals in January of each school year, with a modest (\$100) incentive. Follow-up by mail, e-mail, and telephone continued until recruitment ended in June. The survey consisted of two parts: one that pertained to school-wide practices and policies to be completed by the principal and a second module intended for the school food service manager, regarding foods and beverages sold in competitive venues and at lunch. Items for the current analyses were drawn from the second module. Respondents were asked to indicate the role of the person who completed the surveys; in some cases, this was left blank or a person's name, not a job title/role, was provided. Among the 462 cases where information on respondent role was useable, a food service provider was the primary respondent at 105 schools $(22.8 \%)$ and a secondary respondent at an additional $91(19.7 \%)$. At 238 schools (51.5\%), the principal responded, and at $28(6.0 \%)$, the respondent was a business manager or teacher.

\section{Measures}

The surveys were developed by researchers to be consistent with surveys from an existing, parallel study of practices in middle and high schools, as well as a review of earlier research, and original development of items of interest to the research team.

Lunch characteristics. Respondents were asked to indicate how often each of a list of foods and beverages were available to elementary students in "the school lunch meal (not a la carte)," with response options of $1=$ never, 
$2=$ some days, or $3=$ most or every day. The items include: vegetables (excluding potatoes); fresh fruit; salad bar; premade main course salads; whole grains (such as wheat bread or brown rice); fried potatoes (including reheated French fries or tater tots); regular pizza; and healthier pizza (e.g., whole-wheat crust, lower-fat cheese, and/or toppings). The more-healthful items were collapsed as binary variables to compare "most or every day" versus "some days or never." Regular pizza and fries were collapsed as "never" versus "some days, most days, or every day." A series of items asked about milks at various levels of fat content, with or without flavoring. These items were combined to indicate: (1) whether any higher-fat milks disallowed under the new guidelines were ever offered (i.e., $2 \%$ or whole-fat unflavored or flavored milks, and flavored $1 \%$ milk) and (2) whether any flavored milks were offered.

Perceived reactions to new lunches. Subsequent to the release of the updated USDA standards, six items were added to the 2012-2013 survey to assess perceived reactions to the new meals. The items were developed by the research team based on the researchers' personal experience with and knowledge of lunch practices in schools. However, they were not pretested and were not validated (i.e., perceptions were not validated against objective measures of student participation in meals programs or plate waste). As such, they only represent perceptions, not actual prevalence of students' complaints or changes in meal participation or consumption.

The lead-in stated: "New USDA standards for school meals took effect starting at the beginning of the 20122013 school year, setting requirements about fruit and vegetable availability, whole-grain products, fat and sodium content, and other meals characteristics. Please answer the following questions specifically about changes you have seen since the beginning of the 2012-2013 school year." The first item asked "Compared to this time last year (spring 2012), how many students at your school typically purchase (whether they eat it or not) the school lunch offered through the USDA-reimbursable National School Lunch Program (whether it is purchased at full/ reduced-price or free)?" Responses were: A lot more students; slightly more students; about the same; slightly fewer students; a lot fewer students; and don't know. A second question asked, "Has the percentage of food in lunches that students typically consume each day changed since this time last year?", with responses of: Students are eating a lot more of the food; students are eating slightly more of the food; about the same; students are eating slightly less of the food; students are eating a lot less of the food; and don't know. Four attitude items were measured on a Likert-type scale where $1=$ strongly disagree, $2=$ disagree, $3=$ agree, and $4=$ strongly agree. Respondents were asked to indicate agreement with the statements: "Students generally seem to like the new school lunch," "At first, students complained about the new lunches," "Few students complain about the new lunches," and
"Most students don't seem concerned about the changes in the school lunches."

Contextual factors. School-level demographic data were obtained from public-use data files from the NCES. ${ }^{14}$ These variables, used as covariates in all analyses, included region, locale, school size, student racial/ethnic composition, and student eligibility for free/reducedpriced lunch as an inverse proxy for socioeconomic status (SES). Variables were collapsed as shown in Table 1.

\section{Table I. Demographic Characteristics of Participating US Public Elementary Schools ${ }^{\mathrm{a}}$}

\begin{tabular}{|c|c|c|}
\hline Characteristics & \% schools ${ }^{\mathbf{b}}$ & No. of schoolsc \\
\hline \multicolumn{3}{|l|}{ Region } \\
\hline South & 36.8 & 179 \\
\hline West & 23.8 & 89 \\
\hline Midwest & 24.0 & 155 \\
\hline Northeast & 15.3 & 134 \\
\hline \multicolumn{3}{|l|}{ Locale } \\
\hline Urban & 34.5 & 127 \\
\hline Suburban & 29.9 & $|7|$ \\
\hline Town & 9.6 & 75 \\
\hline Rural & 26.1 & 184 \\
\hline \multicolumn{3}{|l|}{ School size } \\
\hline Large (>621 students) & 22.6 & 109 \\
\hline Medium (45I-62I students) & 31.7 & 177 \\
\hline Small (<45I students) & 45.7 & 271 \\
\hline \multicolumn{3}{|l|}{ Student race/ethnicity } \\
\hline $\begin{array}{l}\text { Predominantly ( } \geq 66 \% \text { ) white } \\
\text { non-Latino }\end{array}$ & 40.5 & 293 \\
\hline Majority ( $\geq 50 \%$ ) black & 13.2 & 53 \\
\hline Majority ( $\geq 50 \%$ ) Latino & 20.7 & 74 \\
\hline Other & 25.6 & 137 \\
\hline
\end{tabular}

Socioeconomic status (based on eligibility

for free/reduced-price meals)

\begin{tabular}{l|c|c|}
\hline $\begin{array}{l}\text { Lower }(>66 \% \text { of students } \\
\text { eligible) }\end{array}$ & 38.0 & 161 \\
\hline $\begin{array}{l}\text { Middle }(>33-\leq 66 \% \text { of } \\
\text { students eligible) }\end{array}$ & 37.2 & 220 \\
\hline $\begin{array}{l}\text { Higher }(\leq 33 \% \text { of students } \\
\text { eligible) }\end{array}$ & 24.9 & 176 \\
\hline
\end{tabular}

${ }^{a} n=557$.

bPercentages are weighted to the school level. Percentages sum by column to 100 within category, but as a result of rounding some may not sum to exactly $100 \%$.

'Number of schools is unweighted. 
Analyses also controlled for whether the primary respondent was a food service provider (vs. administrator/other school staff).

\section{Statistical Analysis}

Analyses were conducted in Stata statistical software (Stata/SE version 12.0; StataCorp, College Station, TX) and accounted for sampling stratum and for the clustering of schools within districts. Data were weighted to provide inference to all US public elementary schools.

\section{Results}

As shown in Table 1, the sample represented a diverse cross-section of schools from all regions of the country, with adequate representation of lower-SES schools. Scores on the six items used to assess perceived reactions were distributed across the full range of responses (see Table 2). Psychometric analyses examined the feasibility of combining the four perceived complaints items for parsimonious use as a single scale score: Principal components analysis showed a strong unitary component (eigenvalue $=1.97$ ). All items had strong item-to-total correlations $(r \mathrm{~s}>0.70)$, and the coefficient alpha for the scale was 0.80 . Items 1, 3, and 4 loaded negatively and were reversescored before averaging. Possible scores ranged from 1.0 to 4.0 , and the distribution of scores was fairly normal ( kurtosis $=2.78$; mean $=2.46$; median $=2.25$ ), so the scale was treated as a continuous variable. Perceived changes in meal purchases and consumption were recoded to center around zero ( a lot fewer/less $=-2$; slightly fewer/less $=-1$; about the same $=0$; slightly more $=1 ;$ a lot more=2) and were treated as roughly continuous variables.

Three multivariate linear regression models were used to examine variations in perceived reactions across schools. Each model controlled for contextual characteristics and respondent role. A consistent pattern of differences emerged by locale, with respondents at rural schools perceiving more student complaints, decreased purchasing, and decreased consumption of lunches. In addition, there were significant differences in perceived purchasing and consumption of lunches, with both variables showing increases at lower-SES schools, as compared to decreases at higher-SES schools. To explore these effects, adjusted margins were computed for each locale and for each SES tertile group, and these represent the average response for each subgroup, controlling for all covariates in the model (see Table 3).

Next, a series of multivariate linear regressions examined the associations between lunch characteristics and perceived student reactions (results not shown in tables). Separately, each lunch characteristic was added to the contextual covariates as predictor variables. The school lunch meal characteristics were binary $(0 / 1)$ variables, and the percentages of schools coded as yes for each were as follows: Offering fresh fruit on most days (76.9\%); offering vegetables other than potatoes on most days $(85.1 \%)$; offering whole grains on most days (49.4\%); ever offering

\section{Table 2. Perceived Reactions to Changes in School Lunch Meals During the 20I2-20I3} School Year, as Indicated by Survey Respondents at a Nationally Representative Sample of US Public Elementary Schools ${ }^{a}$

\begin{tabular}{|c|c|c|c|c|c|c|}
\hline & \multicolumn{5}{|c|}{ Percentage of respondents endorsing each option } & \multirow[b]{2}{*}{$\begin{array}{c}\text { Number of } \\
\text { valid responses }\end{array}$} \\
\hline & $\begin{array}{l}\text { Strongly } \\
\text { disagree }\end{array}$ & Disagree & Agree & $\begin{array}{l}\text { Strongly } \\
\text { agree }\end{array}$ & & \\
\hline $\begin{array}{l}\text { Students generally seem to like } \\
\text { the new school lunch. }\end{array}$ & 5.6 & 24.4 & 62.6 & 7.4 & & 535 \\
\hline $\begin{array}{l}\text { At first, students complained } \\
\text { about the new lunches. }\end{array}$ & 8.6 & 35.0 & 42.7 & 13.7 & & 534 \\
\hline $\begin{array}{l}\text { Few students complain about } \\
\text { the new lunches. }\end{array}$ & 8.2 & 28.2 & 55.4 & 8.2 & & 531 \\
\hline \multirow{2}{*}{$\begin{array}{l}\text { Most students don't seem } \\
\text { concerned about the changes } \\
\text { in the school lunches. }\end{array}$} & 7.8 & 29.0 & 51.9 & 11.3 & & 535 \\
\hline & $\begin{array}{c}\text { A lot } \\
\text { fewer/less }\end{array}$ & $\begin{array}{c}\text { Slightly } \\
\text { fewer/less }\end{array}$ & $\begin{array}{l}\text { About } \\
\text { the same }\end{array}$ & $\begin{array}{l}\text { Slightly } \\
\text { more }\end{array}$ & A lot more & \\
\hline $\begin{array}{l}\text { How many students purchase } \\
\text { lunch, compared to last year? }\end{array}$ & 4.3 & 12.2 & 64.6 & 12.9 & 6.2 & 524 \\
\hline $\begin{array}{l}\text { Any change in the percentage } \\
\text { of the lunch meal that students } \\
\text { consume? }\end{array}$ & 5.1 & 15.8 & 58.6 & 11.2 & 9.2 & 517 \\
\hline
\end{tabular}

${ }^{\mathrm{a}} n=557$. 
Table 3. Elementary School Respondents' Perceptions of Student Reactions to Changes in School Lunch Meals, by School Locale and Socioeconomic Status

\begin{tabular}{l|c|c|c|c|c|c|c|c} 
& \multirow{2}{*}{$\begin{array}{l}\text { Range of } \\
\text { possible } \\
\text { scores }\end{array}$} & $\begin{array}{c}\text { Urban } \\
\text { mean (SE) }\end{array}$ & $\begin{array}{c}\text { Suburban } \\
\text { mean (SE) }\end{array}$ & $\begin{array}{c}\text { Township } \\
\text { mean (SE) }\end{array}$ & $\begin{array}{c}\text { Rural } \\
\text { mean (SE) }\end{array}$ & $\begin{array}{c}\text { Lower } \\
\text { mean (SE) }\end{array}$ & $\begin{array}{c}\text { Medium } \\
\text { mean (SE) }\end{array}$ & $\begin{array}{c}\text { Higher } \\
\text { mean (SE) }\end{array}$ \\
\cline { 3 - 8 } $\begin{array}{l}\text { Perceived complaints } \\
\text { scale }\end{array}$ & I to 4 & $2.25(0.07)^{\mathrm{a}}$ & $2.37(0.07)^{\mathrm{a}}$ & $2.43(0.10)^{\mathrm{a}}$ & $2.69(0.07)^{\mathrm{b}}$ & $2.38(0.06)$ & $2.48(0.06)$ & $2.40(0.08)$ \\
\hline $\begin{array}{l}\text { Perceived change in } \\
\text { number of students } \\
\text { purchasing lunches }\end{array}$ & -2 to +2 & $0.23(0.10)^{\mathrm{a}}$ & $0.16(0.10)^{\mathrm{a}}$ & $0.00(0.14)$ & $-0.24(0.08)^{\mathrm{b}}$ & $0.25(0.09)^{\mathrm{a}}$ & $-0.01(0.07)$ & $-0.15(0.09)^{\mathrm{b}}$ \\
\hline $\begin{array}{l}\text { Perceived change in } \\
\text { amount of lunch meal } \\
\text { consumed }\end{array}$ & -2 to +2 & $0.25(0.12)^{\mathrm{a}}$ & $0.19(0.10)^{\mathrm{a}}$ & $-0.11(0.14)$ & $-0.33(0.10)^{\mathrm{b}}$ & $0.24(0.12)^{\mathrm{a}}$ & $-0.07(0.07)$ & $-0.14(0.11)^{\mathrm{b}}$ \\
\hline
\end{tabular}

Estimates shown are covariate adjusted (i.e., controlling for contextual school characteristics and survey respondent role).

Socioeconomic status (SES) defined by percentage of students eligible for free/reduced-priced meals (lower SES, $>66 \%$ of students eligible; medium SES, $33-\leq 66 \%$ of students eligible; higher SES, $\leq 33 \%$ of students eligible).

Within each category (locale and SES) different superscripts indicate significant differences at $p<0.05$ or better.

Perceived complaints scale coded so that higher scores indicate more complaints; perceived changes in purchasing and consumption coded so that: $-2=a$ lot fewer/less; $-I=$ slightly fewer/less; 0 =about the same; $+I=$ slightly more; $+2=a$ lot more.

SE, standard error.

healthier pizza $(84.9 \%)$; never offering regular pizza (53.1\%); and never offering deep-fried French fries or potatoes $(40.2 \%)$. Salad bars were regularly offered at $28.7 \%$ of schools, and premade main-course salads were regularly offered at $25.8 \%$ of schools. Many schools used either or both of these practices; therefore, the two variables were combined for analysis $(47.1 \%$ of schools offered salad bars and/or premade salads). The percentage of schools offering milks disallowed under the new guidelines was $70.9 \%$. However, in many of these schools, the milks were compliant with the exception of $1 \%$ flavored milks, which are not allowed under the new standards. Only $39.1 \%$ of schools offered $2 \%$ or whole-fat milks, and the other $31.8 \%$ of schools failed to comply with the guidelines only because of the 1\% flavored milks. Flavored milks (at any fat content) were nearly ubiquitous, being offered in $90.4 \%$ of schools.

Scores on the perceived complaints scale were only associated with one practice: not offering regular pizza. Where regular pizza was never offered, respondents perceived more student complaints (adjusted coeff $=0.17$; $p<0.01)$. Perceived change in purchasing was associated with only the availability of vegetables (other than potatoes), with respondents perceiving that more students were purchasing meals, compared to the previous year, at schools where vegetables were offered on most days ( $a d-$ justed coeff $=0.27 ; p<0.05$ ). Perceived change in meal consumption was associated with only the availability of salads, with respondents perceiving that students were eating more of the meal, compared to during the previous year, at schools where salads were offered on most days (adjusted coeff $=0.30 ; p<0.001$ ).
Finally, to test whether perceived student reactions varied by time, a variable to account for the timing of the survey response (winter 2013 versus spring/early summer 2013) was added to the multivariate models, but response timing was not associated with any outcomes.

\section{Discussion}

This study assessed school respondents' perceptions of elementary school students' early reactions to the lunches served subsequent to revisions in the USDA school meals standards. Many aspects of school lunch quality have been improving over time, with many improvements underway even before the 2012-2013 school year. ${ }^{6}$ Although some media reports ${ }^{15-17}$ have described student complaints about the meals, in actuality, very few respondents perceived strong resistance to the changes. Although $13.7 \%$ of respondents "strongly agreed" that at first students complained about the meals, $63.2 \%$ also agreed or strongly agreed that most students are no longer concerned about the meals.

Although not validated against actual plate waste or administrative data on rates of participation in the meals programs, respondent perceptions of whether more or fewer students were buying meals and how much food they were eating also revealed a fairly balanced picture. Only $4.3 \%$ of respondents perceived that "a lot fewer" students were purchasing lunch, whereas $6.2 \%$ perceived that "a lot more" were purchasing lunch. Likewise, consumption estimates were balanced between the extremes of "a lot less" and "a lot more," with most respondents using the middle of the scale. Although this assessment is subjective 
and less precise than objective measures, it does provide relevant data regarding the perceptions of school personnel across the country and allows for the generation of hypotheses that can be tested with administrative data or observational methods. Recent research in urban elementary and middle schools shows that the new NSLP standards increased students' consumption of vegetables and did not result in increased plate waste ${ }^{18}$; nevertheless, lawmakers have expressed concerns about wasted food in school meals ${ }^{19,20}$ and, therefore, additional research is needed to assess changes in consumption.

One significant area of concern illuminated by the current data is that rural schools fared worse than urban or suburban schools in terms of the issues examined here: perceived student complaints about new meals, purchasing of meals, and consumption of meals. This is particularly important, given the higher rates of childhood obesity in rural areas, ${ }^{21}$ as well as an overall reduced life expectancy among rural populations and a widening rural-urban life expectancy gap. ${ }^{22}$ In addition, schools in small towns and rural areas have significantly fewer policies to support healthy school environments - particularly with regard to fruit and vegetable availability - than do urban or suburban schools. $^{23}$ Speculation as to the reasons for greater implementation challenges in rural schools is beyond the scope of the current data; therefore, future work is essential for further understanding this important health disparity.

Another key health disparity was noted with regard to perceived changes in purchasing and consumption of meals. At schools serving higher proportions of socioeconomically disadvantaged students, respondents perceived that more students were purchasing the meal and that students were consuming more of the meal, as compared to the previous year. This is consistent with the conclusions of the GAO study, ${ }^{13}$ speculating that students dropping out of the meals programs were those paying full price, rather than the students receiving subsidized meals. Previous work shows that paid meal participation rates are affected by meal prices, ${ }^{6,24,25}$ with an estimated $1.5 \%$ decrease in full-price lunch participation with each $10 \%$ increase in the price of lunches. ${ }^{6}$ Additional studies are needed to examine the longitudinal associations between changes in meal prices and student participation rates. The current data offer some encouraging news that schools serving primarily lower-income students may not be seeing disproportionately adverse effects of the new meals standards, in terms of student uptake. Over the past three decades, student participation rates in the NSLP were quite stable, at $50-58 \%$ of students, but during periods of economic decline the proportion of students who participated at free or reduced-price status increased. ${ }^{26}$ As one key element of the nation's child nutrition programs, the NSLP provides a safety net for socioeconomically disadvantaged families, particularly during challenging economic times, such as the past few years. It is possible that widespread implementation of national policy has been effective for improving the diets of socioeconomically disadvantaged children, but more research is needed to understand the effect of changes in the meal standards on children's participation and dietary intake and also to examine how changing prices affect these key outcomes.

With regard to associations between meal characteristics and student reactions, perceived complaints were higher at schools that did not offer regular pizza. The current data also indicate a decrease in the prevalence of regular pizza in school lunches: In 2006-2007, we found that $98 \%$ of public elementary schools offered pizza on some or most days. ${ }^{27}$ The current data show that $46.9 \%$ of schools now offer regular pizza, and $84.9 \%$ of schools offer healthier pizzas, suggesting that pizza has not been removed from lunch lines, but rather has been reformulated in ways to make it healthier. Student complaints were not associated with the availability of healthier pizza, just the absence of regular pizza, suggesting possible pushback as a consequence of changing menu options.

Often, new policy initiatives are met with objections and some resistance, but, over time, norms change and individuals adapt to changing environments. Lunchroom interventions based on behavioral economics (i.e., attending to the presentation of fruits and vegetables and serving healthful foods first in lunch lines) can improve children's food consumption choices and behaviors, ${ }^{28-30}$ and thus such strategies hold great promise to improve the effectiveness of policy implementation, in terms of actually changing student behaviors. Although anecdotal stories of students refusing to eat meals are concerning, and they draw media attention, ${ }^{15,16}$ school personnel actually seem to be more neutral about the effect of the new meals. Given the possible threat of legislation to roll back these new meal standards, it is crucial to base policy decisions on data, rather than on rhetoric. The current data show that purchasing may have increased where vegetables were offered, and respondents estimated that consumption of meals was slightly higher than in previous years where healthier options, such as salad, were regularly offered. Other work also shows that new meals standards have increased students' consumption of non-potato vegetables, without resulting in increased plate waste. ${ }^{18}$

The current conclusions are subject to several important limitations. Survey data can be affected by social desirability bias or lack of complete knowledge. Although the analytic weights were adjusted for potential nonresponse bias, some factors may have systematically biased which schools responded. The data were cross-sectional, and thus we were unable to compare changes in the number of students participating in the meals programs in 2012-2013, as compared to previous years; archival data are needed to track changes in the number of students who purchase meals from year to year. As noted earlier in the article, the current conclusions are based on respondent perceptions, rather than objectively measured data regarding meal purchases or plate waste. The survey respondents were a mix of mostly food service providers and school administrators; although at most elementary schools the administrator 
spends time in the lunchroom and keeps a pulse on the climate of the school (i.e., being aware of student complaints), their perspectives may differ from those of food service providers. Finally, it is important to note that this study only considered elementary schools, but not secondary schools; older students may have had different reactions to the new meals.

\section{Conclusions}

The perceptions of elementary school personnel regarding the effect of new meals on student purchasing and consumption patterns suggest little change overall in student behaviors subsequent to the revised USDA meals standards. Although many respondents agreed that students complained at first, most also agreed that few students now complain about the lunches. Greater challenges were perceived by respondents at rural schools, highlighting the need for future work to understand and address health disparities in rural communities. Given the importance of offering healthful foods to young children while at school, the revised USDA meals standards are a promising strategy to improve the diets of children.

\section{Acknowledgment}

Research support was provided by the Robert Wood Johnson Foundation.

We thank Ms. Anna Sandoval.

\section{Author Disclosure Statement}

No competing financial interests exist.

\section{References}

1. Clark MA, Fox MK. Nutritional quality of the diets of US public school children and the role of the school meal programs. $J$ Am Diet Assoc 2009;109:S44-S56.

2. Guenther PM, Dodd K, Reedy J, et al. Most Americans eat much less than recommended amounts of fruits and vegetables. $J \mathrm{Am}$ Diet Assoc 2006;106:1371-1379.

3. Krebs-Smith SM, Guenther PM, Subar AF, et al. Americans do not meet federal dietary recommendations. J Nutr 2010;140:1832-1838.

4. Holman DM, White MC. Dietary behaviors related to cancer prevention among pre-adolescents and adolescents: The gap between recommendations and reality. Nutr $J$ 2011;10:60.

5. Poti JM, Slining MM, Popkin BM. Solid fat and added sugar intake among US children: The role of stores, schools, and fast food, 1994-2010. Am J Prev Med 2013;45:551-559.

6. Fox MK, Condon E. School Nutrition Dietary Assessment IV: Summary of findings. 2012. Available at www.mathematicampr.com/publications/PDFs/nutrition/snda-iv_findings.pdf Last accessed April 2, 2014.

7. United States Department of Agriculture, Food and Nutrition Service. Fact sheet: National School Lunch Program. 2013. Available at www.fns.usda.gov/sites/default/files/NSLPFactSheet .pdf Last accessed April 2, 2014.
8. United States Department of Agriculture. The Healthy, HungerFree Kids Act of 2010. 2013. Available at www.fns.usda.gov/cnd/ Governance/ Legislation/CNR_2010.htm Last accessed April 2, 2014.

9. United States Department of Agriculture and United States Department of Health and Human Services. Dietary Guidelines for Americans 2010. US Government Printing Office: Washington, DC, 2010.

10. United States Department of Agriculture. Nutrition standards in the National School Lunch and School Breakfast programs: Final rule. 2012. Available at www.gpo.gov/fdsys/pkg/FR-2012-01-26/ pdf/2012-1010.pdf Last accessed April 2, 2014.

11. United States Department of Agriculture, Food and Nutrition Service. National School Lunch Program and School Breakfast Program: Nutrition standards for all foods sold in school as required by the Healthy, Hunger-Free Kids Act of 2010. Interim final rule. Fed Regist 2013;78:39067-39120.

12. Byker CJ, Pinard CA, Yaroch AL, et al. New NSLP guidelines: Challenges and opportunities for nutrition education practitioners and researchers. J Nutr Educ Behav 2013;45:683-689.

13. Government Accountability Office. School lunch: Implementing nutrition changes was challenging and clarification of oversight requirements is needed. GAO-14-104. Available at www.gao.gov/ products/GAO-14-104 Last accessed April 2, 2014.

14. National Center for Education Statistics. Common core of data. Available at http://nces.ed.gov/ccd/ccddata.asp Last accessed June 9, 2014.

15. Yee V. No appetite for good-for-you school lunches. The New York Times. October 5, 2012. Available at www.nytimes.com/2012/10/ 06/nyregion/healthier-school-lunches-face-student-rejection.html? pagewanted = all Last accessed May 2, 2014.

16. Hellmich N. Students push back on new lunches. USA Today September 28, 2012. Available at http://usatoday30.usatoday.com/ news/nation/story/2012/09/28/kids-push-back-on-new-school-lunch/ 57842204/1 Last accessed May 2, 2014.

17. Jalonick MC. Schools seek changes to healthier lunch rules Available at http://bigstory.ap.org/article/schools-seek-changeshealthier-lunch-rules-0 Last accessed May 5, 2014.

18. Cohen JFW, Richardson S, Parker E, et al. Impact of the new US Department of Agriculture school meal standards on food selection, consumption, and waste. Am J Prev Med 2014;46:388-394.

19. Mitka M. Nutrition and school lunches. JAMA 2013;309:973.

20. Mitka M. Meal programs questioned. JAMA 2012;308:1849.

21. Lutfiyya MN, Lipsky MS, Wisdom-Behounek J, et al. Is rural residency a risk factor for overweight and obesity for US children? Obesity 2007;15:2348-2356.

22. Singh GK, Slahpush M. Widening rural-urban disparities in life expectancy, US, 1969-2009. Am J Prev Med 2014;46:e19-e29.

23. Nanney MS, Davey CS, Kubik MY. Rural disparities in the distribution of policies that support healthy eating in US secondary schools. J Acad Nutr Diet 2013;113:1062-1068.

24. Dragoset L, Gordon A. Selecting policy indicators and developing simulation models for the National School Lunch and Breakfast programs: Final report. Report no. CN 10-PRED. Washington, DC: USDA, Food and Nutrition Service, June 2010.

25. Moore Q, Hulsey L, Ponza M. Factors associated with school meal participation and the relationship between different participation measures. Contractor and cooperator report no. 53. Washington, DC: USDA, Economic Research Service, June 2009.

26. Hanson K, Oliveira K. How economic conditions affect participation in USDA nutrition assistance programs. Report EIB-100. Washington, DC: USDA, Economic Research Service, September 2012.

27. Turner L, Chaloupka FJ, Sandoval A. School policies and practices for improving children's health: National Elementary School Survey 
results: School years 2006-07 through 2009-10. Vol. 2. Bridging the Gap Program, Health Policy Center, Institute for Health Research and Policy, University of Illinois at Chicago: Chicago, IL, 2012

28. Hanks AS, Just DR, Wansink B. Smarter lunchrooms can address new school lunchroom guidelines and childhood obesity. $J$ Pediatr 2013;162:867-869.

29. Wansink B, Hanks AS. Slim by design: Serving healthy foods first in buffet lines improves overall meal selection. PLoS One 2013; 8:e77055.

30. Wansink B, Just DR, Hanks AS, et al. Pre-sliced fruit in school cafeterias: Children's selection and intake. Am J Prev Med 2013; 44:477-480.
Address correspondence to:

Lindsey Turner, PhD

Research Associate Professor

College of Education

Boise State University

1910 University Drive

Boise, ID 83725

E-mail: lindseyturner1@boisestate.edu 